\title{
Associations between Maturity Status and Dietary Intake in Austrian Adolescents
}

\author{
Clemens Drenowatz ${ }^{1 *}$ and Klaus Greier ${ }^{2,3}$ \\ ${ }^{1}$ Division of Physical Education, University of Education Upper Austria, Austria \\ ${ }^{2}$ Division of Physical Education, Private Educational College (KPH-ES), Austria \\ ${ }^{3}$ Department of Sport Science, Leopold-Franzens-University Innsbruck, Austria
}

*Corresponding author: Clemens Drenowatz, Division of Physical Education, University of Education Upper Austria, Kaplanhofstrasse 404020 Linz, Austria, Tel: +43-(0)732/7470-7426

\begin{abstract}
Background: Dietary intake plays an important role in the development and health of children and adolescents. Puberty is a particularly vulnerable period due to the increased nutrient demands associated with growth. This age range has also been associated with various changes in health behavior. While several studies have examined the influence of the social and built environment on dietary habits during adolescence, there remains limited research on the association between biological maturation and eating behaviors as well as food intake in youth.

Methods: This cross-sectional study includes data from 165 participants (55\% male) between 11 and 16 years of age. The study protocol was approved by the University of Innsbruck Institutional Review Board as well as the school board and principals of the participating schools. Body weight and height was measured with an electronic scale and a portable stadiometer during a regular physical education class with participants wearing gym clothes and being barefoot. Subsequently, maturity offset was calculated, and biological maturation was determined based on estimated age at peak height velocity. A standardized questionnaire administered during regular class-time was used to assess dietary intake and eating habits. Principal component analysis revealed 3 main factors for food intake (meat/carbohydrates, milk/cereal, water/low fast food), which were used in the analyses.
\end{abstract}

Results: There were no differences in eating habits between boys and girls. Boys, however, displayed higher scores for the meat/CHO factor while their scores for the water/low fast food factor was lower compared to girls. There was no difference in eating habits or dietary intake across maturity tertiles in boys. Late maturing girls, however, reported less frequent lunch and dinner as well as higher milk/cereal factor scores compared to their peers.
Conclusion: Biological maturation appears to contribute to changes in dietary intake and eating habits, particularly in girls. Late maturing girls may be at particular risk for irregular eating patterns. Family meals, therefore, may be an important component in the establishment of healthy dietary patterns in adolescents.

\section{Keywords}

Eating habits, Food consumption, Eating pattern, Maturation, Youth

\section{Introduction}

Dietary intake has been associated with the risk for various chronic diseases and plays an important role in the development of children and adolescents [1]. In addition to its role in the regulation of body weight [2], there is evidence for an association of eating behavior with cognitive function, memory, academic performance and psychological well-being [3-5]. Adolescence is a particularly vulnerable period due to the increased nutritional requirements for growth and maturation, which are exceeding those of adults [1]. In addition, adolescence is characterized by behavioral changes due to an increased social and economic independence and development of identity $[6,7]$.

During the last decades there have been significant changes in lifestyle patterns in adolescents, which also affect eating habits. An increasing number of advertisements, specifically targeting youth most likely contributed to alterations in eating behaviors and 
dietary intake [8]. Secular trends showed an increase in the contribution of snacks to total energy intake as well as foods consumed away from home, resulting in more irregular eating patterns $[9,10]$. Accordingly, adolescents have reported fewer meals taken together with the family and to skip breakfast more often $[8,11,12]$, which could have contributed to a high number of adolescents consuming too much meat and sweets while their consumption of fruit and vegetable is too low $[8,13,14]$. Family meals can be an important contributor to the establishment of healthy eating habits as they allow parents to limit access to highly processed foods and to serve as role models for healthy dietary choices [15]. Similarly, breakfast consumption has been shown to play an important role in dietary choices as regular breakfast consumption in adolescents has been associated with a higher micronutrient intake and a greater likelihood of meeting dietary guidelines [12,16-18]. Epidemiological studies further indicate a protective effect of breakfast consumption against overweight and obesity in youth $[16,19-21]$ but intervention studies have failed to demonstrate a causal relationship between regular breakfast consumption and body weight $[22,23]$.

Particularly during adolescence, a variety of factors, including food availability, costs, parental modelling, convenience, peer influences, body image, personal and cultural beliefs, affect dietary choices [24]. Several studies have examined the associations of the social and built environment as well as personal characteristics, such as sex or age, with dietary intake and eating behavior [2527]. Limited research, however, considered the potential influence of biological maturation on eating behaviors and dietary intake. Biological maturation describes the progress towards the mature state, which affects several organic systems and varies in timing and tempo across individuals [28]. Puberty is a stage prone to changes in various behaviors [7] and early onset of puberty has been associated with several unhealthylifestyle choices, including lower rates of breakfast consumption [29]. Dietary habits have also been shown to track from adolescence into adulthood [30,31]. A better understanding of the role of biological maturation on dietary choices, therefore, could provide important information for the mapping of dietary interventions in adolescents. The present study, therefore, examines potential differences in eating behaviors and food intake between early, average and late maturing Austrian adolescents.

\section{Methods}

A convenience sample of 9 middle school classes between grades 6 and 8 in the Federal State of Tyrol, Austria were contacted for participation for this crosssectional study. All students in the selected classes, who were physically able to perform the motor competence test were eligible for participation in the study, which resulted in a sample size of 172 participants between 11 and 16 years of age. Parents received written information about the nature of the study and provided written informed consent. Students gave oral consent at the time of data collection after all procedures were explained. The study protocol was approved by the Institutional Review Board of the University of Innsbruck as well as the school board of the Federal State of Tyrol and the principals of the participating schools. Data collection occurred during May and June of 2018.

\section{Anthropometric measurements}

Trained technicians measured body weight $(\mathrm{kg})$ and height $(\mathrm{cm})$ during a physical education class according to standard procedures. Measurements were taken with participants in gym clothes and being barefoot. Body weight was measured to the nearest $0.1 \mathrm{~kg}$ with a gauged body scale $\left(\right.$ SECA $^{\circledR}$ 803, Seca, Hamburg, Germany) and height was measured to the nearest $0.1 \mathrm{~cm}$ with a mobile stadiometer (SECA ${ }^{\circledR} 217$, Seca, Hamburg, Germany). Body mass index (BMI) was calculated (weight in kilograms divided by the square of height in meters, $\mathrm{kg} / \mathrm{m}^{2}$ ) and converted to BMI percentiles based on the German reference system [32].

\section{Maturity status}

Maturity status was determined using estimated age at peak height velocity (APHV) as the onset of adolescent growth sport coincides with the onset of puberty [33]. A recent study further showed that anthropometric measurements (i.e. body height and weight) can be used to provide accurate estimations of APHV [34]. Specifically, maturity offset, which indicates years from peak height velocity was calculated using the following equations [34]:

Maturity Offset $_{\text {boys }}=-7.999994+[0.0036124 \times$ (age (years) $\times$ height $(\mathrm{cm}))] ; \mathrm{R}^{2}=0.896$

Maturity Offset ${ }_{\text {girls }}=-7.709133+[0.0042232 \times$ (age (years) $\times$ height $(\mathrm{cm}))] ; \mathrm{R}^{2}=0.898$

Subsequently estimated APHV was calculated (APHV = chronological age - maturity offset) and participants were stratified into early, average or late maturers based on sex specific sample tertiles.

\section{Eating habits and food intake}

Dietary information was obtained via a previously used standardized food frequency questionnaire that was administered by a trained technician during regular class time [35]. Participants reported the number of days they consumed various foods and drinks during a regular week. Dietary patterns were determined via principal component analysis (PCA). PCA revealed 3 factors with an Eigenvalue $>1$, which explained $55.9 \%$ of the total variance of food consumption. The 3 factors were characterized by high loadings of meat, fish, bread, pasta and sweets consumption (meat/CHO); high loadings of milk, cereal, nuts and fruits (milk/cereal); and high consumption of water and vegetables as well as low consumption fast food (FF) and softdrink (water/ 
low FF). Participants also reported the average number of days per week they consumed breakfast, lunch and dinner along with the number of days per week they consumed snacks in between meals and after dinner.

\section{Statistical analyses}

Descriptive statistics were calculated for anthropometric characteristics and dietary habits separately for boys and girls. Sex differences were determined via ANOVA for continuous variables (anthropometric measurements, diet factors) and Mann-Whitney-U tests for ordinal variables (eating habits). Differences in dietary intake by maturity status were examined separately for boys and girls using ANCOVA, adjusting for chronological age and using Bonferroni adjustment for post-hoc analyses. Differences in eating habits between maturity tertiles were examined using Kruskal-Wallis Tests, separately for boys and girls. All statistical analyses were performed using SPSS 24.0 (IBM, Armonk, NY).

\section{Results}

Valid data was provided by 165 adolescents (55.2\% male) between 11 and 16 years of age. Of the total sample, $20.4 \%$ were overweight/obese. There were no sex differences in overweight/obesity rates and BMI percentiles. Boys, however, were taller and heavier than girls, which may have been attributed to their older age (Table 1).

Eating habits did not differ between boys and girls. Daily breakfast consumption was reported by $52 \%$ of the participants and $71 \%$ of the participants reported breakfast consumption on 5 days per week. Daily lunch and dinner was reported by $85 \%$ and $70 \%$ of the participants, respectively. A majority $(80 \%)$ of the participants reported having morning snacks on at least 5 days per week while only $22 \%$ reported afternoon snacks at least 5 times per week. Late night snacks on 5 or more days per week were reported by only $8 \%$ but $46 \%$ of the participants reported having a late-night snack at least once a week. Despite a lack of difference in eating habits, boys displayed higher scores on the meat/ $\mathrm{CHO}$ factor ( $p=0.020$ ) while their scores on the water/ low FF factor was lower $(p=0.006)$ compared to girls.

Table 1: Anthropometric characteristics and estimated age at peak height velocity (est. APHV) for the total sample and separately for boys and girls. Values are Means \pm SD.

\begin{tabular}{|c|c|c|c|c|}
\hline & $\begin{array}{l}\text { Total sample } \\
\text { (N=165) }\end{array}$ & $\begin{array}{l}\text { Girls only } \\
(N=74)\end{array}$ & $\begin{array}{l}\text { Boys only } \\
(\mathrm{N}=91)\end{array}$ & $p$-value \\
\hline Age (years) & $13.5 \pm 1.1$ & $13.2 \pm 1.0$ & $13.7 \pm 1.1$ & 0.015 \\
\hline Height (cm) & $161.3 \pm 8.9$ & $158.8 \pm 6.8$ & $163.4 \pm 9.9$ & 0.001 \\
\hline Weight (kg) & $53.8 \pm 14.3$ & $51.3 \pm 9.9$ & $55.9 \pm 16.9$ & 0.043 \\
\hline BMI percentile & $59.4 \pm 29.4$ & $60.9 \pm 27.5$ & $58.2 \pm 31.0$ & 0.563 \\
\hline Est. APHV (years) & $12.9 \pm 0.8$ & $12.1 \pm 0.4$ & $13.6 \pm 0.4$ & $<0.001$ \\
\hline
\end{tabular}

p-value indicates differences between boys and girls.

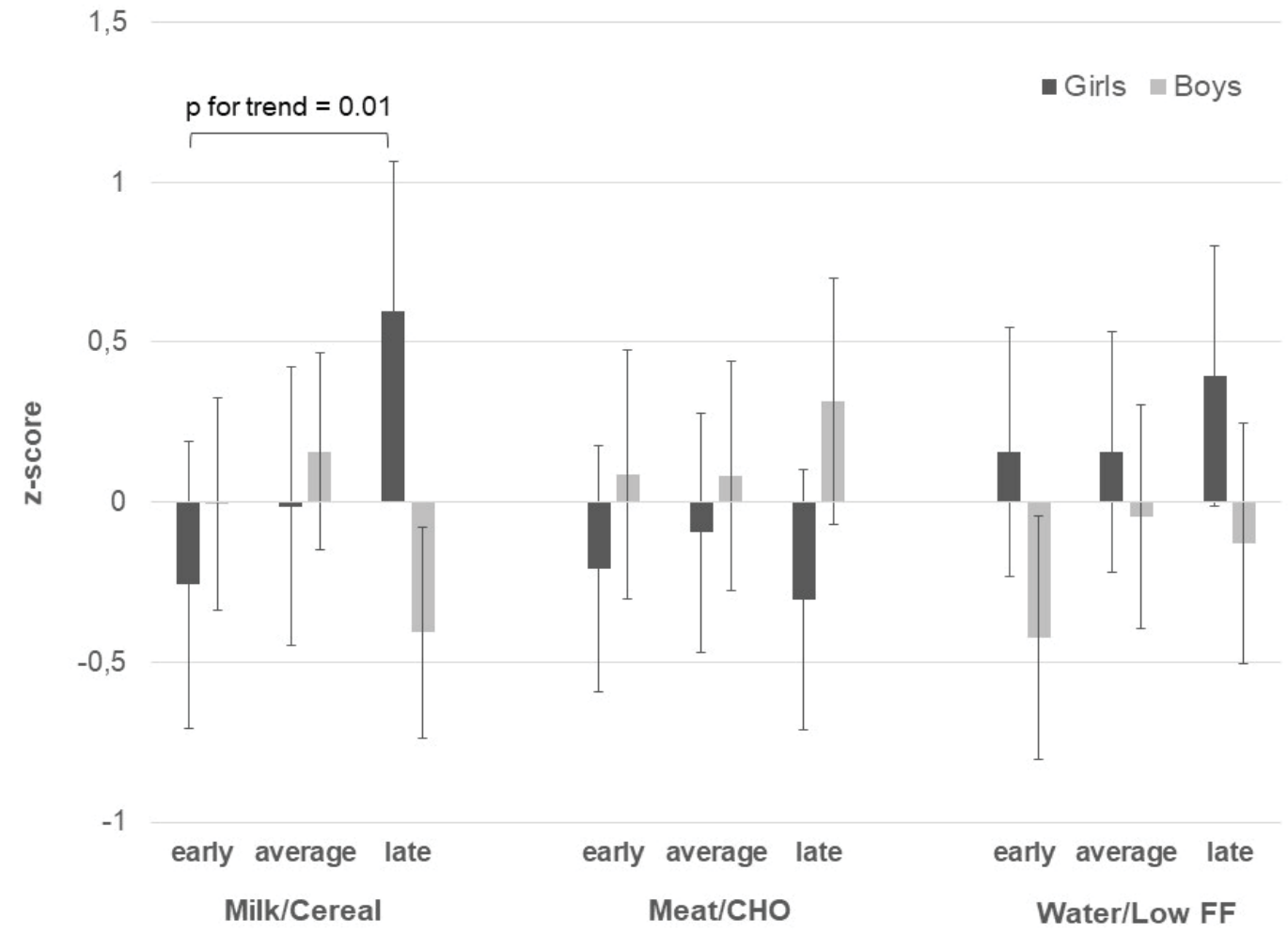

Figure 1: Differences in diet factors by maturity status in boys and girls. Values are Means adjusted for age with $95 \% \mathrm{Cl}$. 
Maturity status was associated with body height. Specifically, early maturing boys and girls were taller than their average or late maturing peers $(p<0.001)$ but there were no differences in body weight and BMI percentile across maturity tertiles. Milk/cereal consumption was higher with later maturation in girls ( $p$ for trend $=0.007$ ). Differences in milk/cereal consumption in boys were borderline significant with higher milk/cereal consumption in average maturers compared to their early or late maturing peers $(p=$ 0.051) (Figure 1). No significant differences across maturity groups were observed for the meat/CHO or water/low FF factor scores in either girls or boys.

The frequency of regular meals differed significantly

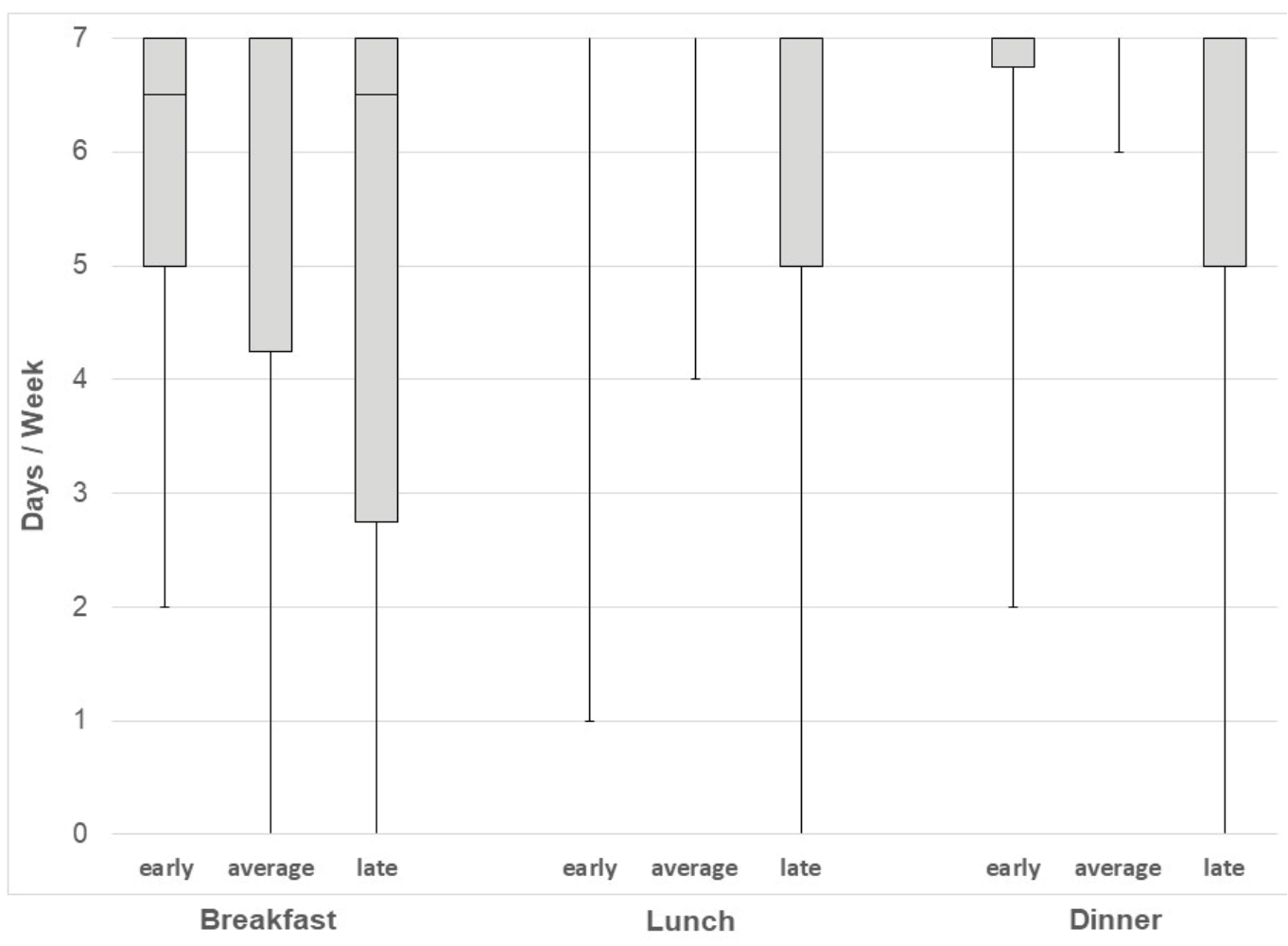

Figure 2: Boxplot for consumption (days/week) of major meals by maturity status in girls.

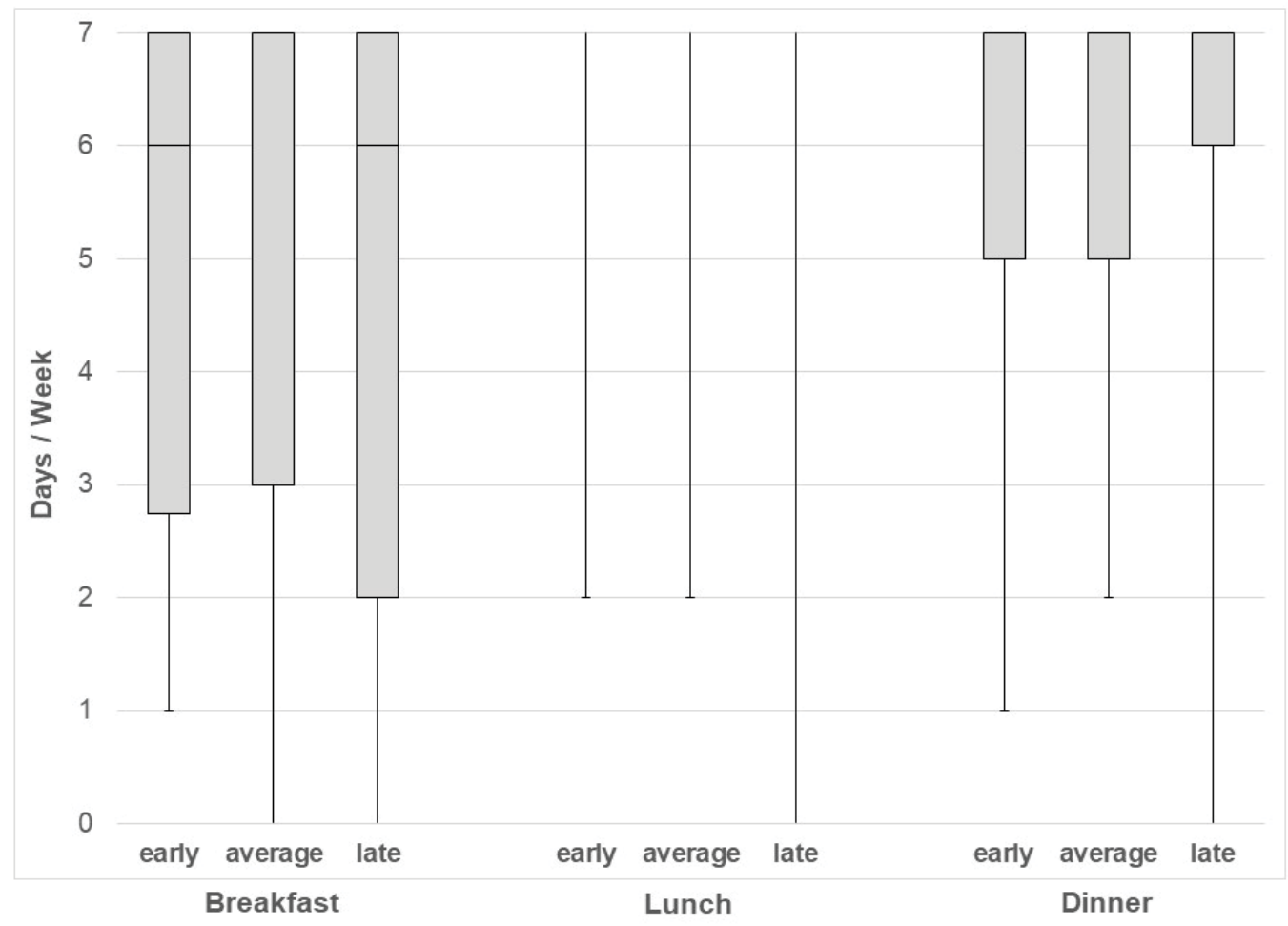

Figure 3: Boxplot for consumption (days/week) of major meals by maturity status in boys. 
across maturity tertiles in girls but not in boys (Figure 2 and Figure 3). Specifically, late maturing girls reported less frequent lunches $(p=0.007)$ and dinners $(p=0.024)$ compared to their peers. No significant differences across maturity tertiles were observed for snack frequency in either girls or boys.

\section{Discussion}

To the authors knowledge this was the first study to examine differences in dietary intake and eating behaviors (i.e. frequency of various meals during the week) by maturity status in Austrian adolescents. Several interesting insights were obtained which could provide valuable information for intervention strategies that promote healthy eating in adolescents. There were no sex differences in eating habits and a majority of the participants reported daily lunch and dinner. Nevertheless, girls displayed healthier dietary choices compared to boys, which has been reported previously. Harris, et al., for example, showed a greater protein and fat intake in adolescent boys compared to girls [27]. Further, girls have been shown to decrease their meat consumption while increasing fruit and vegetable intake with increasing age, while boys increased their softdrink consumption as they progressed through puberty $[27,36,37]$. These sex differences in dietary intake may be attributed to a greater consciousness about dietary choices in girls due to concerns about body image, which become more pronounced during adolescence [38,39]. Accordingly, women have been shown to be more conscious about their dietary intake than men [40]. Differences in concerns about dietary intake may also explain the sex differences in the associations between eating behaviors and maturity status, which were the focus of the present study.

In boys, associations between maturational timing and dietary intake as well as eating behaviors were limited. Late maturing girls, on the other hand, reported less frequent lunches and dinners and displayed more frequent milk/cereal consumption compared to their average or early maturing peers. A study in Swedish adolescents also indicated a greater tendency for dietary modifications during puberty in females while changes in dietary intake were less common in boys [37]. The overserved decline in milk intake with increasing age in the Swedish cohort is also consistent with the less frequent milk/cereal consumption of early adolescent girls in the present study. As food choice is a complex behavior, biological as well as social and cultural factors may contribute to these differences by maturity status $[7,40]$. From a social perspective, early maturing girls may select foods that they consider more adult-like and cereals could be considered a typical food for children. In addition, increased concerns about body weight may contribute to declines in milk consumption [37]. Further, biological needs differ by maturity status. In the present study, late maturing girls were closer to APHV and, therefore had increased calcium needs for growth and accretion of bone [41], which may have resulted in an increased biological drive to consume certain foods such as milk.

Differences in leisure time behaviors by maturity status may also contribute to differences in dietary intake and eating behaviors in girls. Late maturing girls have been shown to be more physically active and more likely to participate in sports compared to their peers [42]. The loss of interest in physical activity (PA) and sports can be at least partially be attributed to changes in physical and functional characteristics that are associated with maturation, which are generally considered hindering successful participation in sports. Specifically, early maturation has been associated with greater body weight relative to their height, which affects various motor tasks [43] as well as alterations in self-concept, and social interactions [44]. Accordingly, female athletes in several sports have been characterized by late biological maturation [45]. Regular training times after school in late maturing girls may hinder a regular eating schedule and potentially increase the likelihood for skipping lunch or dinner. Irregular eating patterns, however, have been associated with less healthy food choices [46] and given the importance of adequate nutrition for growth and development, particularly in active children, healthy eating habits should be encouraged in adolescents. Accordingly, structured meals should still be emphasized even with tight schedules. Family dinners have been associated with higher fruit and vegetable consumption as well as fiber and micronutrient intake while the consumption of softdrinks, fried foods, saturated and trans-fat was lower [47]. Unfortunately, the present study does not provide information on foods consumed during specific meals and there is no information on the amount of food consumed during individual meals. It may, therefore, still be possible that late maturing girls compensate for missed main meals by higher caloric intakes during snacks even though there were no differences in the frequency of snacks by maturity status.

Besides the lack of information on caloric intake, some additional limitations of the present study should be considered when interpreting the results. Dietary questionnaires have an inherent risk of selective overor underreporting due to social desirability and social approval. There may also be problems in remembering all foods consumed during the last week and participants may have consumed some foods that were not listed on the questionnaire, which would affect the displayed dietary intake of the sample. These problems, however, are common with dietary reports and the administration of the questionnaire by a trained technician during regular class-time should have contributed to more accurate reports. The reliance on an indirect measure of maturity status along with a small range of estimated APHV may also have contributed to the limited 
significant findings. Body weight and height, however, were measured by trained technicians and somatic measurements have been shown to provide accurate estimates of maturation, particularly in age groups that are close to APHV [34], which was the case in the present study.

In conclusion, the results of the present study indicate that maturity status affects eating behavior and food choices, particularly in girls. As adolescents are prepared to change their dietary habits in different directions during puberty, this may be an opportune time for the promotion of healthy eating habits $[7,37]$. Due to the increased contribution of snacks to overall dietary intake, foods that contribute to meeting dietary guidelines and support healthy growth and development should be promoted in schools as well as after-school settings. In addition, family meals remain an important component in the establishment of healthy dietary habits in adolescents. More research, including longitudinal data, however, is needed to enhance the understanding of the interaction between maturation and eating habits as well as food choices. Such information could also provide crucial information for the development of interventions targeting healthy dietary choices and enhance overall health and wellbeing in adolescents.

\section{Funding}

No funding has been received this study and the preparation of this manuscript.

\section{References}

1. Moreno LA, Rodriguez G, Fleta J, Bueno-Lozano M, Lazaro A, et al. (2010) Trends of dietary habits in adolescents. Crit Rev Food Sci Nutr 50: 106-112.

2. Pérez-Escamilla R, Obbagy JE, Altman JM, Essery EV, McGrane MM, et al. (2012) Dietary energy density and body weight in adults and children: A systematic review. J Acad Nutr Diet 112: 671-684.

3. Cooper SB, Bandelow S, Nevill ME (2011) Breakfast consumption and cognitive function in adolescent schoolchildren. Physiol Behav 103: 431-439.

4. Maffeis C, Fornari E, Surano MG, Comencini E, Corradi M, et al. (2012) Breakfast skipping in prepubertal obese children: Hormonal, metabolic and cognitive consequences. Eur J Clin Nutr 66: 314-321.

5. Sánchez-Villegas A, Toledo E, de Irala J, Ruiz-Canela M, Pla-Vidal J, et al. (2012) Fast-food and commercial baked goods consumption and the risk of depression. Public Health Nutr 15: 424-432.

6. Das JK, Salam RA, Thornburg KL, Prentice AM, Campisi S, et al. (2017) Nutrition in adolescents: Physiology, metabolism, and nutritional needs. Ann N Y Acad Sci 1393: 21-33.

7. Todd AS, Street SJ, Ziviani J, Byrne NM, Hills AP (2015) Overweight and obese adolescent girls: The importance of promoting sensible eating and activity behaviors from the start of the adolescent period. Int J Environ Res Public Health 12: 2306-2329.

8. Mensink GB, Kleiser C, Richter A (2007) Food consumption of children and adolescents in Germany. Results of the German Health Interview and Examination Survey for Children and Adolescents (KiGGS). Bundesgesundheitsblatt Gesundheitsforschung Gesundheitsschutz 50: 609-623.

9. Piernas C, Popkin BM (2010) Trends in snacking among U.S. children. Health Aff (Millwood) 29: 398-404.

10. Piernas C, Popkin BM (2011) Food portion patterns and trends among U.S. children and the relationship to total eating occasion size, 1977-2006. J Nutr 141: 1159-1164.

11. Weber E, Hiebl A, Storr U (2008) Overweight and obesity in children starting school in Augsburg: Prevalence and influencing factors. Dtsch Arztebl Int 105: 883-889.

12. Coulthard JD, Palla L, Pot GK (2017) Breakfast consumption and nutrient intakes in 4-18-year-olds: UK National Diet and Nutrition Survey Rolling Programme (2008-2012). Br J Nutr 118: $280-290$.

13. Ogden CL, Carroll MD, Kit BK, Flegal KM (2014) Prevalence of childhood and adult obesity in the United States, 20112012. JAMA 311: 806-814.

14. Krebs-Smith SM, Guenther PM, Subar AF, Kirkpatrick SI, Dodd KW (2010) Americans do not meet federal dietary recommendations. J Nutr 140: 1832-1838.

15. Pearson N, Biddle SJ, Gorely T (2009) Family correlates of breakfast consumption among children and adolescents. A systematic review. Appetite 52: 1-7.

16. Rampersaud GC (2009) Benefits of breakfast for children and adolescents: Update and recommenations for practitioners. Am J Lifestyle Med 3: 86-103.

17. Deshmukh-Taskar PR, Nicklas TA, O'Neil CE, Keast DR, Radcliffe JD, et al. (2010) The relationship of breakfast skipping and type of breakfast consumption with nutrient intake and weight status in children and adolescents: The National Health and Nutrition Examination Survey 19992006. J Am Diet Assoc 110: 869-878.

18. Fayet-Moore F, Kim J, Sritharan N, Petocz P (2016) Impact of breakfast skipping and breakfast choice on the nutrient intake and body mass index of australian children. Nutrients 8: E487.

19. Szajewska H, Ruszczynski M (2010) Systematic review demonstrating that breakfast consumption influences body weight outcomes in children and adolescents in Europe. Crit Rev Food Sci Nutr 50: 113-119.

20. Haug E, Rasmussen M, Samdal O, lannotti R, Kelly C, et al. (2009) Overweight in school-aged children and its relationship with demographic and lifestyle factors: Results from the WHOCollaborative Health Behaviour in School-aged Children (HBSC) study. Int J Public Health 54: 167-179.

21. de la Hunty A, Gibson S, Ashwell M (2013) Does regular breakfast cereal consumption help children and adolescents stay slimmer? A systematic review and meta-analysis. Obes Facts 6: 70-85.

22. Dhurandhar EJ (2016) True, true, unrelated? A review of recent evidence for a causal influence of breakfast on obesity. Curr Opin Endocrinol Diabetes Obes 23: 384-388.

23. van Nassau F, Singh AS, Cerin E, Salmon J, van Mechelen W, et al. (2014) The Dutch Obesity Intervention in Teenagers (DOiT) cluster-controlled implementation trial: Intervention effects and mediators and moderators of adiposity and energy balance-related behaviours. Int J Behav Nutr Phys Act 11: 158.

24. Story M, Stang J (2005) Understanding adolescent eating behaviors. In: M Story, J Stang, Guidelines for Adolescent Nutrition Services. Center for Leadership, Education and 
Training in Maternal and Child Nutrition: Minneapolis, MN, 9-19.

25. Jodhun BM, Pem D, Jeewon R (2016) A systematic review of factors affecting energy intake of adolescent girls. Afr Health Sci 16: 910-922.

26. Berge JM, Wall M, Larson N, Forsyth A, Bauer KW, et al. (2014) Youth dietary intake and weight status: healthful neighborhood food environments enhance the protective role of supportive family home environments. Health Place 26: 69-77.

27. Harris C, Flexeder C, Thiering E, Buyken A, Berdel D, et al. (2015) Changes in dietary intake during puberty and their determinants: Results from the GINIplus birth cohort study. BMC Public Health 15: 841.

28. Malina RM, Bouchard C, Bar-Or O (2004) Growth, maturation, and physical activity. ( $2^{\text {nd }}$ edn), Human Kinectics, Champaign, IL.

29. van Jaarsveld CH, Fidler JA, Simon AE, Wardle J (2007) Persistent impact of pubertal timing on trends in smoking, food choice, activity, and stress in adolescence. Psychosom Med 69: 798-806.

30. Kelder SH, Perry CL, Klepp KI, Lytle LL (1994) Longitudinal tracking of adolescent smoking, physical activity, and food choice behaviors. Am J Public Health 84: 1121-1126.

31. Lien N, Lytle LA, Klepp KI (2001) Stability in consumption of fruit, vegetables, and sugary foods in a cohort from age 14 to age 21. Prev Med 33: 217-226.

32. Kromeyer-Hauschild K, Wabitsch M, Kunze D, Geller F, Geiß HC, et al. (2001) Perzentile für den Body-massIndex für das Kindes- und Jugendalter unter Heranziehung verschiedener deutscher Stichproben. Monatsschr Kinderheilkd 149: 807-818.

33. Rogol AD, Clark PA, Roemmich JN (2000) Growth and pubertal development in children and adolescents: Effects of diet and physical activity. Am J Clin Nutr 72: 521S-528S.

34. Moore SA, McKay HA, Macdonald H, Nettlefold L, BaxterJones $A D$, et al. (2015) Enhancing a somatic maturity prediction model. Med Sci Sports Exerc 47: 1755-1764.

35. Greier K, Ruedlet G, Weber C, Thöni G, Riechelmann H (2016) Ernährungsverhalten und motorische Leistungsfähigkeit von 10 - bis 14-jährigen Jugendlichen. $E$ \& $M$ - Ernährung und Medizin 31: 166-171.
36. Libuda L, Alexy U, Sichert-Hellert W, Stehle P, KaraolisDanckert N, et al. (2008) Pattern of beverage consumption and long-term association with body-weight status in German adolescents-results from the DONALD study. $\mathrm{Br} \mathrm{J}$ Nutr 99: 1370-1379.

37. Von Post-Skagegård $M$, Samuelson G, Karlström B, Mohsen R, Berglund L, et al. (2002) Changes in food habits in healthy Swedish adolescents during the transition from adolescence to adulthood. Eur J Clin Nutr 56: 532-538.

38. Smolak $L$ (2004) Body image in children and adolescents: Where do we go from here? Body Image 1: 15-28.

39. Dennison CM, Shepherd R (1995) Adolescent food choice: An application of the theory of planned behaviour. J Human Nutr Dietet 8: 9-23.

40. Arganini C, Saba A, Comitato R, Virgili F, Turrini A (2012) Gender differences in food choice and dietary intake in modern western societies. In: J Maddock, Public healthsocial and behavioral health. InTech, Rijeka, Croatia.

41. Cashman KD (2002) Calcium intake, calcium bioavailability and bone health. Br J Nutr 87: S169-S177.

42. Werneck AO, Silva DR, Collings PJ, Fernandes RA, Ronque ERV, et al. (2018) Biocultural approach of the association between maturity and physical activity in youth. $\mathrm{J}$ Pediatr (Rio J) 94: 658-665.

43. Brown KA, Patel DR, Darmawan D (2017) Participation in sports in relation to adolescent growth and development. Transl Pediatr 6: 150-159.

44. Cumming $S$ (2013) New directions in the study of maturation and physical activity. In: P Katzmarzyk, M Coelho, E Silva, Growth and maturation in human bioogy and sports. Imprensa da Universidade de Coimbra, Portugal, 129-138.

45. Beunen GP, Rogol AD, Malina RM (2006) Indicators of biological maturation and secular changes in biological maturation. Food Nutr Bull 27: S244-S256.

46. Sjöberg A, Hallberg L, Höglund D, Hulthén L (2003) Meal pattern, food choice, nutrient intake and lifestyle factors in The Göteborg Adolescence Study. Eur J Clin Nutr 57: 1569-1578.

47. Gillman MW, Rifas-Shiman SL, Frazier AL, Rockett HR, Camargo CA Jr, et al. (2000) Family dinner and diet quality among older children and adolescents. Arch Fam Med 9: 235-240. 